\title{
SOBRE LA PRESENCIA YAUSENCIA DE LA -E PARAGÓGICA EN LOS ROMANCES \\ CAROLINGIOS IMPRESOS DURANTE EL PERÍODO POSTINCUNABLE
}

\author{
Joan Mahiques Climent \\ Universitat Jaume I - GREMI \\ jmahique@uji.es
}

\section{Introducción}

No solamente en el romancero, sino también en cantares de gesta y canciones de corte tradicional, se documenta el fenómeno de la -e paragógica, que consiste en la adición de esta vocal al final de las palabras-rima agudas para conseguir de este modo una rima regular paroxítona integrada por vocablos cuya terminación podría ser en unos casos natural y en otros casos artificiosa, como sucede, por ejemplo, entre ciudades y ciudade o entre comendadores y comendadore $^{1}$. El incremento vocálico que se aplica a las formas agudas podría justificarse unas veces como un arcaísmo propio de la lengua castellana medieval, pero en muchas otras ocasiones se concreta en una construcción morfológica claramente antietimológica que nada tiene que ver con las variedades diacrónicas o diatópicas y que, en cambio, responde al criterio formal y estilístico de preservar la regularidad de metro y rima grave.

Ahora bien, prácticamente todos los testimonios donde se documenta este recurso presentan una clara desproporción entre el escaso número de palabras llanas propias del castellano (por ejemplo, madre o hombre) y la gran abundancia de vocablos agudos susceptibles de incorporar dicho apéndice

\footnotetext{
${ }^{1}$ En el romancero, la -e paragógica solía añadirse a las rimas oxítonas $-a$ y $-o$, aunque también se aplicó de manera más ocasional sobre la $-i$ aguda. En este artículo únicamente estudiaremos este recurso cuando se añade justo después de una - $a$ tónica a final de verso.
} 
vocálico, como sucedería al transformar las formas verbales van y son en vane y sone.

Este desequilibrio cuantitativo puede oscilar según los romances y los testimonios que se tomen en consideración, pero hasta el momento no hemos encontrado ningún caso en que las palabras-rima llanas sin paragoge superen el $25 \%$. Además, esta cifra se alcanza únicamente en algunos de los testimonios del Romance del conde Dirlos sin llegar en ningún caso a rebasar el umbral del $26 \%$. El hecho de que las palabras-rima artificiosas alcancen los índices de mayor frecuencia nos permite caracterizar la -e paragógica no como un procedimiento ocasional para adaptar esporádicamente un verso a la métrica y a la rima de un determinado romance, sino como un fenómeno estructural que afecta en su globalidad a la obra poética en cuestión. Además, el número inferior de palabras-rima llanas sin ningún incremento parece indicar que el método compositivo de estos romances conllevaba considerar la -e añadida no como una licencia para encontrar más fácilmente una rima sino como un precepto poético con el que se pretendía obtener un determinado efecto estilístico. Hacia esta misma dirección apuntan algunos datos que vinculan este recurso a la juglaría y al canto. No deja de ser significativo que el manuscrito único del Cantar de Mio Cid incorpore muy ocasionalmente dicho incremento en posición de rima; o que en la Gramática castellana de Nebrija, publicada en 1492, se especifique que «los que lo cantan, porque hallan corto y escaso aquel último espondeo, suplen y rehazen lo que falta, por aquella figura que los gramáticos llaman paragoge..., y por coraçón y son dizen coraçone y sone ${ }^{2} \gg$.

A partir de este pasaje de Nebrija, Ramón Menéndez Pidal se opuso frontalmente a una teoría desarrollada por algunos de los más destacados exponentes de la crítica filológica decimonónica, los cuales acusaban a los impresores quinientistas por haber perpetrado el uso de la -e paragógica, que consideraban impropio del antiguo romancero castellano. A Ferdinand Wolf debemos una de las primeras lanzas arrojadas en favor de esta última hipótesis. Este romanista austríaco expuso por primera vez su punto de vista en un

\footnotetext{
${ }^{2}$ Apud Ramón Menéndez Pidal, Romancero hispánico (hispano-portugués, americano y sefardi), 2 vols., Madrid, Espasa-Calpe, 1953, vol. I, p. 110. En las pp. 110-121, Menéndez Pidal analiza a fondo el fenómeno de la -e paragógica. Véase también Ninfa Criado, «La /E/ paragógica», en Anuario de Estudios Filológicos, 35 (2002), pp. 69-82. Sobre la presencia de este recurso en el Cantar de Mío de Cid y en la Gramática de Nebrija, remitimos a Ana M. Gómez Bravo, «La naturaleza de las asonancias del Cantar de mío Cid. Notas sobre la -e paragógica», en Hispania, 81/3 (septiembre 1998), pp. 501-508; y Dorothy Clotelle Clarke, «Nebrija on versification», en Publications of the Modern Language Association of America, 72:1 (1957), pp. 27-42. Esta última estudiosa puntualiza: «It is worth noting that Nebrija considers line length and not rime the reason for the use of the paragogic $e »$ (p. 34).
} 
estudio escrito en alemán; posteriormente, reincidió en lo mismo tanto en el estudio introductorio como en la edición de la Primavera y flor de los mejores romances (1856), donde procedió a eliminar sistemáticamente la -e paragógica de los romances publicados en los dos volúmenes de esta renombrada compilación ${ }^{3}$.

¿Pero la -e paragógica es realmente un artificio que debemos atribuir a los impresores quinientistas, o más bien estamos ante una característica propia de estos romances que no hemos podido documentar antes debido a la falta de testimonios? La crítica actual, y el sentido común, coinciden en considerar la -e paragógica como un fenómeno propio de los romances en cuestión desde sus mismos orígenes, y no como un elemento impostado a posteriori en un momento determinado de su proceso de transmisión textual. Si de algo debemos responsabilizar a los impresores no es del hecho de haber aplicado el recurso de la -e paragógica a los romances, sino más bien de lo contrario: los impresores fueron en gran medida quienes procedieron a sustituir rimas llanas paragógicas por las correspondientes rimas agudas.

Por eso mismo, la presencia y la ausencia de la -e paragógica están estrechamente ligadas a los inicios de la imprenta en España, sobre todo a partir de la segunda década del siglo XVI, justo cuando se produce una conjunción de varios factores decisivos que dispararon la difusión del romancero y de sus modalidades a través de la imprenta. Uno de los principales factores en cuestión es, sin duda, la eclosión del pliego suelto poético, un producto tipográfico que estaba al alcance de un público muy amplio y diversificado.

En este artículo nos proponemos dilucidar hasta qué punto y de qué modo la imprenta influyó directamente en el uso y la difusión de la -e paragógica ${ }^{4}$. Para llevar a cabo nuestro cometido, nos centraremos específicamente en la materia carolingia, ya que es ahí donde se manifiesta con mayor frecuencia este recurso estilístico. Consideramos que son romances carolingios aquellos que se refieren al emperador Carlomagno, a los doce Pares de Francia o a otros personajes y contextos que se relacionan estrechamente con estos

\footnotetext{
${ }^{3}$ Fernando José Wolf y Conrado Hoffman, Primavera y flor de romances o colección de los más viejos y más populares romances castellanos, 2 vols., Berlín, Asher y Comp., 1856, vol. I, pp. v-VI. Como Ferdinand Wolf, Reinhart Dozy $(\uparrow 1883)$ y Andrés Bello $(† 1865)$ consideraban que la -e paragógica era un artificio tardío, culpa de impresores del siglo xvi. Opinión a la cual se opuso Amador de los Ríos aduciendo el susodicho ejemplo de la Gramática de Nebrija que vinculaba la -e paragógica al canto. Véase José Amador de los Ríos, Historia crítica de la literatura española, Madrid, José Rodríguez, 1862, vol. II, pp. 478-480.

${ }^{4}$ Sobre la eclosión del pliego poético postincunable como medio de transmisión, remitimos a Vicenç Beltran, «Los primeros pliegos poéticos: alta cultura / cultura popular», en Revista de Literatura Medieval, 17 (2005), pp. 71-120; y Laura Puerto Moro, «El universo del pliego poético postincunable (del despegue de la literatura popular impresa en castellano)», en eHumanista, 21 (2012), pp. 257-304.
} 
asuntos. Estas composiciones suelen recuperar, pues, personajes y temas de la épica francesa y se adscriben en su mayoría al romancero juglaresco y a sus particularidades estilísticas ${ }^{5}$. A continuación, procederemos a analizar las rimas de estos romances teniendo en cuenta los datos tipográficos de sus testimonios impresos (lugar, impresor y fecha). De este modo, podremos establecer una serie de tendencias prioritarias que tenían determinados impresores sin renunciar a un marco cronológico más general en el que se pueden ver algunos cambios o repuntes en el uso y difusión de la -e paragógica vinculada al romancero.

\section{Criterios metodológicos y recopilación de datos}

Este estudio sobre el uso de la -e paragógica se basa en la recopilación y análisis de diversos datos relativos tanto a las rimas de los romances como a los impresos que los transmiten. Para delimitar este corpus textual, se ha procedido a la consulta y selección de los romances carolingios publicados por Giuseppe Di Stefano en una antología que aspira a reunir en su conjunto todo el romancero conservado a través de testimonios anteriores al año 1521; hemos excluido de nuestro corpus no solamente los textos de los que no nos ha llegado ningún testimonio impreso de este período sino también las copias manuscritas de los romances carolingios seleccionados 6 . Queda claro, pues, que nuestra atención está plenamente focalizada en el ámbito de la imprenta. Como resultado de este procedimiento se han clasificado los siguientes romances, que mencionamos según el mismo orden numérico en que están dispuestas las tablas de romances carolingios al final de este artículo. Hemos procedido a regularizar gráficamente el íncipit de cada romance.

\section{1] Romance de Gaiferos libertador de Melisenda «Asentado está Gaiferos en el palacio real» (Di Stefano, n. ${ }^{\circ}$ 100)}

\footnotetext{
${ }^{5}$ En consonancia con lo que acabamos de exponer, Vladimír Honsa considera que uno de los factores que propiciaron la formación de la -e paragógica como recurso estilístico es «the influence of Old French epic poems causing an imitation of their feminine assonance and rhyme», Vladimír Honsa, «Old Spanish paragogic -e», en Hispania 45:2 (mayo 1962), pp. 242-246 (p. 245). Según dicho estudioso, esto se manifestaría a través del romancero carolingio y de la épica castellana.

${ }^{6}$ Giuseppe Di Stefano, Romances, I. El primer siglo del romancero en el papel: c. 1421-1520, Würzburg-Madrid, Clásicos Hispánicos (ePub), 2017. En este volumen se editan varios romances con - $e$ paragógica que hemos excluido de nuestro estudio o bien porque no se han documentado en impresos anteriores a 1521 o bien porque nos han llegado en estado fragmentario o bien porque no se adscriben claramente a la materia carolingia. Entre los excluidos, está el fragmento manuscrito de cuatro versos que dice: «Los braços trayo cansados / de los muertos rodear; / fallo todos los franceses, / no fallo a don Reinalte» (p. 389, n. ${ }^{\circ}$ 96).
} 
SOBRE LA PRESENCIA Y AUSENCIA DE LA -E PARAGÓGICA EN LOS ROMANCES...

2] Romance del conde Guarinos

«Mala la vistes, franceses, la caza de Roncesvalles» (Di Stefano, n. ${ }^{\circ}$ 97)

3] Romance del moro Calaínos

«Ya cabalga Calaínos a sombra de una oliva» (Di Stefano, n. ${ }^{\circ} 107$ )

4] Romance del conde Dirlos

«Estábase el conde Dirlos, sobrino de don Beltrane» (Di Stefano, n. ${ }^{\circ}$ 102)

5] Romance de Melisenda insomne

«Todas las gentes dormían en las que Dios había parte» (Di Stefano, n. ${ }^{\text {7) }}$

6 y 7] Romances del marqués de Mantua

«De Mantua salió el marqués Danés Urgel el leal» (Di Stefano, n. ${ }^{\circ}$ 103)

«De Mantua salen apriesa sin tardanza ni vagar» (Di Stefano, n. ${ }^{\circ} 104$ )

8] Romance del rey Malsín

«Ya comienzan los franceses con los moros pelear» (Di Stefano, n. ${ }^{\circ}$ 95)

9] Romances de Gaiferos

«Medianoche era pasada y otra media por pasar» (Di Stefano, n. ${ }^{\circ}$ 99)

10] Romance de los doce Pares de Francia

«En misa está el emperador allá en san Juan de Letrán» (Di Stefano, n. ${ }^{\circ}$ 108)

11] Romance de Guiomar y del emperador Carlos

«Ya se sale Guiomar de los baños de bañar» (Di Stefano, n. ${ }^{\circ}$ 106)

Una vez establecido el elenco de romances carolingios, se ha procedido a crear unas tablas que contengan la información que consideramos relevante de cara al análisis propuesto. Cada tabla incluye los datos básicos sobre el romance (título e íncipit regularizados), sobre sus testimonios impresos quinientistas (títulos, asignaciones tipográficas y bibliografía) y sobre las rimas con o sin -e paragógica. Las referencias bibliográficas, que en las tablas aparecen de manera abreviada, se completan en una breve nota en la última sección del artículo. El análisis de los datos se fundamenta en la atribución de unas determinadas tendencias o prácticas en función de la época, del lugar y de la imprenta, teniendo en cuenta también la influencia que ejercieron unos testimonios sobre otros y considerando además la información que poseemos sobre el stemma de algunos romances, las relaciones de dependencia entre algunos de sus testimonios y las características, fuentes y tradición literaria de 
los especímenes examinados. Todos ellos se han conservado como mínimo en un pliego poético postincunable, pero las tablas no incluyen únicamente las fuentes anteriores a 1521 sino también todos los pliegos poéticos del siglo XVI que hemos podido localizar y consultar en su integridad, así como los textos correspondientes del Cancionero de romances de Martín Nucio y las partes segunda y tercera de la Silva de Esteban G. de Nájera: el Cancionero salió en Amberes sin indicar la fecha, aunque sabemos que fue en 1546 o 1547, mientras que las mencionadas partes de la Silva se publicaron en Zaragoza, la segunda en 1550 y la tercera al año siguiente ${ }^{7}$. La selección de estos romanceros impresos viene determinada por la gran influencia que ejercieron en el contexto literario de la segunda mitad del siglo XVI, no solamente por el hecho de haber sido objeto de numerosas reediciones y refundiciones, sino también por ser ascendentes de muchos de los pliegos poéticos que se fueron publicando a partir de entonces.

El resultado de esta investigación depende en buena medida de la fiabilidad de la información que ofrecemos en las tablas, motivo por el cual hemos adoptado algunas medidas para asegurar la solvencia de estos datos, ya sean relativos a las rimas de los romances o a las asignaciones de lugar, impresor y fecha de cada una de las ediciones quinientistas. Por eso mismo hemos desestimado los testimonios fragmentarios o aquellos que, hallándose en bibliotecas privadas de difícil acceso, no hemos consultado en su integridad: de otro modo, podría quedar desvirtuada la estadística derivada de la ponderación cuantitativa de los porcentajes de las rimas con -e paragógica o sin ella ${ }^{8}$.

\footnotetext{
${ }^{7}$ A partir de ahora utilizaremos las siglas CR[47], 2S50 y 3S51 para referirnos respectivamente al cancionero antuerpiense, a la Parte segunda de la silva de varios romances y a la Parte tercera de la silva de varios romances. Sobre la datación de CR[47], véase Josep Lluís Martos, «La fecha del Cancionero de romances sin año», en Edad de Oro, 36 (2017), pp. 137-156. Hemos consultado el cancionero y las silvas a través de los facsímiles de Ramón Menéndez Pidal, Cancionero de romances impreso en Amberes sin año [ed. facsímil: Amberes, Martín Nucio], Madrid, Junta para Ampliación de Estudios-Centro de Estudios Históricos, 1914; Vicenç Beltrán, Segunda parte de la silua de varios romances [ed. facsímil: Zaragoza, Esteban G. de Nájera, 1550], México, Frente de Afirmación Hispanista, 2017; e Id., Tercera parte de la Silua de varios Romances [ed. facsímil: Zaragoza, Esteban G. de Nájera, 1551], México, Frente de Afirmación Hispanista, 2017.

${ }^{8}$ Todas las referencias que a partir de ahora haremos a través de las siglas RM y Supl. RM se refieren respectivamente a los asientos de Antonio Rodríguez-Moñino, Nuevo Diccionario Bibliográfico de Pliegos Sueltos Poéticos (Siglo XVI), ed. corregida y actualizada por Arthur L.-F. Askins y Víctor Infantes, Madrid, Castalia-Editora Regional de Extremadura, 1997; Arthur L.-F. Askins, Víctor Infantes y Laura Puerto Moro, Suplemento al Nuevo diccionario bibliográfico de pliegos sueltos poéticos (siglo XVI) de Antonio Rodríguez-Moñino, Vigo, Academia del Hispanismo, 2014. Hay dos pliegos fragmentarios, RM 1171 y RM 1172, que transmiten respectivamente el Romance de los doce Pares de Francia y el Romance del conde Dirlos. También hemos excluido algunos pliegos poéticos pertenecientes a bibliotecas privadas, como el que reseña Mercedes Fernández Valladares, «Descripciones y estudio bibliográfico», en Pliegos sueltos poéticos del siglo XVI en bibliotecas de Francia [ed. facsímil], ed. de Mercedes Fernández Valladares, Laura Puerto Moro y Joan Mahiques Climent, México, Frente de Afirmación Hispanista, 2 vols.,
} 
Igualmente, hemos excluido de las tablas algunos pliegos poéticos por el simple hecho de que no han sido consultados a lo largo de esta investigación, sobre todo porque no contamos con ediciones facsímiles 9 .

En cuanto a las indicaciones tipográficas, debemos destacar que la mayor parte de los pliegos poéticos reseñados en las tablas no indican explícitamente la cronología, el lugar y el taller donde se publicaron. Afortunadamente, contamos con algunos estudios de gran fiabilidad que completan la información que falta en cada una de las ediciones. A este respecto debemos destacar que la mayor parte de los romances carolingios que hemos reseñado cuentan con algún testimonio que se halla entre los pliegos poéticos custodiados en la Bibliothèque nationale de France o en el Musée Condé de Chantilly; y en todos estos casos hemos tenido el privilegio de poder consultar un riguroso estudio llevado a cabo por Mercedes Fernández Valladares, donde se revisan algunas de las asignaciones tipográficas propuestas hasta el momento y también se reúne la bibliografía sobre cada uno de los pliegos, con las respectivas atribuciones señaladas en estudios precedentes sobre la imprenta del siglo XVI ${ }^{10}$.

Finalmente, debemos exponer de manera sucinta en qué se concretan los datos relativos a las rimas paragógicas o no paragógicas. Consideramos que son rimas paragógicas aquellas que incorporan una -e final átona a palabras que en el castellano de la época eran oxítonas. Como ya hemos indicado, este incremento no se aplicaba únicamente sobre los vocablos agudos con rima asonante en - $a$, pero esta última rima es la única a la cual se añade la -e paragógica de todos los romances carolingios que estudiaremos, y eso es así hasta tal punto que podemos concluir que este recurso aplicado al romancero carolingio siempre da como resultado una rima asonante grave en -á.e. Tampoco podemos olvidar que la rima -áee no siempre deriva de una paragoge, ya que en estos mismos romances de reiteran con mucha frecuencia algunas palabras llanas que se ciñen a esta misma rima sin que al final se les aplique ningún incremento vocálico, como sucede con padre, madre, emperante, linaje, grande, pares y ciudades. Por tanto, en relación con el fenómeno que

en prensa, n. ${ }^{\circ}$ XLI. Bajo este ítem se identifica un ejemplar que incluye el Romance de Gaiferos libertador de Melisenda con el pliego RM 999, que poseyó Vicente Salvá.

${ }^{9}$ No hemos consultado el pliego poético RM 610.3, una edición burgalesa datada hacia 1563 con los Romances del marqués de Mantua cuyo ejemplar localizado forma parte de la Bancroft Library. El acceso a otros pliegos poéticos ha sido posible gracias a la inestimable ayuda de otros investigadores, que nos han facilitado reproducciones digitales de algunos de ellos. Debemos la consulta de RM 421, RM 994 y RM 1000 a la gentileza de Vicenç Beltran, Josep Lluís Martos y Mercedes Fernández Valladares.

${ }^{10}$ Mercedes Fernández Valladares, «Descripciones y estudio bibliográfico», ob. cit. De este estudio deriva la mayor parte de la información tipográfica señalada en las tablas de romances carolingios, donde también se incluyen otras referencias bibliográficas a partir de las cuales hemos establecido la cronología e imprenta de cada uno de los pliegos poéticos y romanceros analizados. 
estamos estudiando, podemos hallar tres tipos de terminaciones que en las tablas son representadas a través de las tres primeras columnas sobre palabras-rima: -á $\cdot e$ no paragógica (por ejemplo, emperante), -áce paragógica (por ejemplo, Beltrane), -á (por ejemplo, Beltrán). A estas tres columnas se añade una cuarta columna que se refiere a cualquier otra rima documentada en los testimonios analizados: en la mayor parte de los casos, esta cuarta columna da constancia de irregularidades y posibles errores de transmisión, pero no siempre, ya que en el Romance de Calaínos refleja la superposición de varias series asonantes en la misma balada.

\section{Sobre el uso de la - $e$ paragógica en los testimonios impresos de roman- ces carolingios}

Iniciamos ahora el análisis de los romances carolingios y de sus testimonios impresos a partir de los datos suministrados en las tablas que cierran este artículo. El primer aspecto que puede destacarse es que solamente cinco de los romances analizados cuentan con testimonios donde predomina la rima grave paragógica sobre la rima aguda en -á:

1] Romance de Gaiferos libertador de Melisenda (RM 1001, RM 991);

4] Romance del conde Dirlos (RM 1020, RM 1019, Supl. RM 1023, CR[47], 2S50);

6 y 7] Romances del marqués de Mantua (RM 608, RM 971, CR[47], 2S50);

11] Romance de Guiomar y del emperador Carlos (RM 1008.5).

La presencia de la -á no alcanza el $15 \%$ en ninguno de los testimonios señalados, mientras que el uso de la -e paragógica oscila aproximadamente entre el $70 \%$ y el $98 \%$. Los romances 1 y 4 son los que tienen un porcentaje mayor de rimas no paragógicas en -áe: un $18 \%$ del total en Gaiferos libertador de Melisenda y un $25 \%$ en el Conde Dirlos. De este último romance, Vaquero ha destacado algunos recursos que lo emparentan con la épica medieval, como son el lenguaje formulario -un $49 \%$ del total-, las expresiones hiperbólicas, algunas fórmulas adverbiales de lugar y tiempo, el uso del discurso directo, las enumeraciones juglarescas y el uso abundante de la -e paragógica. A este último recurso debería añadirse, tal como acabamos de señalar, la presencia de la rima -áe no paragógica en un grado muy superior 
al de cualquier otro de los romances que estamos analizando. Todos estos recursos permiten vincular el Conde Dirlos con la oralidad ${ }^{11}$.

En Gaiferos libertador de Melisenda, el porcentaje de rimas no paragógicas en -á e, que asciende a un $18 \%$, es poco más o menos el mismo que encontramos en otros dos romances mucho más breves supuestamente protagonizados por los mismos personajes: nos referimos al Romance de Melisenda insomne y al Romance de Gaiferos. Se trata de dos baladas bastante breves donde se dibuja una escena nocturna similar que no tiene parangón en el resto de los romances que estamos analizando. Dejados a un lado estos casos, la tendencia general es que, en los romances carolingios con -e paragógica, la rima -á e no paragógica se sitúe alrededor del $10 \%$ del total.

Fijémonos ahora en la correlación que existe entre los datos tipográficos de los testimonios impresos y la presencia o ausencia de la -e paragógica. Llama la atención que los siete pliegos postincunables asignados al taller sevillano de Jacobo Cromberger eliminan de manera sistemática cualquier rastro de la -e paragógica, aunque mantienen, como no puede ser de otro modo, algunas palabras-rima en $-\dot{a} \cdot e^{12}$. Tres de los cuatro romances impresos en estos siete pliegos también nos han llegado a través de otros testimonios postincunables, todos burgaleses y con la misma tendencia a eliminar sistemáticamente la -e paragógica. De hecho, en los pliegos burgaleses anteriores a CR[47] se nota una cierta continuidad en el prurito por eliminar la rima paragógica de aquellos romances que fueron impresos previamente en el taller crombergiano $^{13}$. Y también predomina la rima aguda en -á en otros impresos anteriores a CR[47] cuyos romances no se han documentado entre los pliegos crombergianos, tal como sucede en RM 653 y RM 312 con Melisenda insomne, en RM 990 con El rey Malsín y Gaiferos, y en RM 1065 y RM 1084 con Los doce Pares de Francia. En cambio, hay otros dos pliegos burgaleses anteriores a CR[47], que transmiten el Romance del conde Dirlos y los Romances del marqués de Mantua, donde predomina el uso de la -e paragógica en detrimento de la rima aguda en -á. Cabe destacar que estos romances también se documentan en otros dos postincunables, asignados no a Sevilla sino a

${ }^{11}$ Mercedes Vaquero, «Épica francesa y épica española en el Romançe del conde Dirlos», en Historias y ficciones: Coloquio sobre la literatura del siglo XV (Valencia, 29-31 octubre 1990), ed. de Rafael Beltrán, José Luis Canet y Josep Lluís Sirera, València, Universitat de València (Departament de Filologia Espanyola), 1992, pp. 93-110. Donde se puede leer la siguiente afirmación: «es posible que el autor del Dirlos compusiera su cantar oralmente, o tal vez el texto del primer pliego suelto donde apareció provenga de un texto dictado por un juglar que lo sabía de memoria» (p. 101).

${ }^{12}$ RM 995 [+996], RM 997, RM 994, RM 1026, RM 1028, RM 1029 y RM 1008.

${ }^{13}$ RM 1000, RM 993, RM 1065, RM 669 y RM 1030. 
Zaragoza y Valladolid ${ }^{14}$. En conclusión, hay un contraste entre los pliegos sevillanos postincunables y los burgaleses, ya que los primeros, todos impresos por Jacobo Cromberger, presentan una gran regularidad en la supresión de la paragoge, mientras que los pliegos burgaleses ofrecen diversas soluciones en función del romance y de sus testimonios precedentes.

La publicación de CR[47] marca un cambio en el proceso de transmisión de los romances a través de pliegos poéticos. A partir de entonces comienzan a proliferar los cancioneros impresos, entre otros las tres partes de la Silva de varios romances publicadas por Esteban G. de Nájera (1550-1551), con lo cual el pliego poético ha de compartir su espacio de influencia junto con el romancero impreso. En muchas ocasiones, los pliegos poéticos sacan el texto de sus romances a partir de CR[47] y de otras compilaciones al uso, pero esta relación de influencias también se produce en sentido inverso.

Además, en algunos romances se produce una transmisión paralela en la que los cancioneros impresos reproducen un texto diferente del que encontramos en los pliegos poéticos. Así sucede en el Romance de Gaiferos libertador de Melisenda, cuyo stemma ha reconstruido Di Stefano ${ }^{15}$ : el testimonio de 2S50 deriva de CR[47], mientras que este último se relaciona con el arquetipo, que resulta ser RM 995 [+996]. Los dos cancioneros susodichos presentan las mismas rimas no paragógicas en $-a ́ \cdot e$ : en total ascienden a 51 para cada testimonio. En cambio, los pliegos se agrupan en diferentes ramas. Son valencianos RM 1001 y RM 991 y, aunque a nivel numérico no mantienen las mismas proporciones en las rimas, son los únicos testimonios analizados que incluyen el verso con -e paragógica: «y le sacaua de necessidade» (RM 1001, v. 375); «le sacaua de necessidade» (RM 991, v. 374).

Aparte de los dos pliegos que acabamos de mencionar, hay otros testimonios valencianos que restituyen la -e paragógica: nos referimos a RM 971 y Supl. RM 1008.5, con El marqués de Mantua y Guiomar y el emperador Carlos. RM 991 y RM 971, dos pliegos impresos por Álvaro Franco, deben contarse entre los precedentes más semejantes de los respectivos testimonios de Gaiferos libertador de Melisenda y El marqués de Mantua tal como fueron

\footnotetext{
${ }^{14}$ Transmiten el Conde Dirlos con -e paragógica tanto el postincunable zaragozano RM 1020 como los pliegos burgaleses RM 1019 y Supl. RM 1023, ambos impresos por Juan de Junta en la tercera década del siglo XVI. Se mantiene un desfase cronológico similar con los Romances del marqués de Mantua impresos en los pliegos RM 607 [+606] y Supl. RM 608, asignados el primero a Valladolid?, Arnao Guillén de Brocar, 1515-1519?; y el segundo a Burgos, Juan de Junta, 1531 a quo, pero el testimonio vallisoletano elimina la -e paragógica mientras que el burgalés la mantiene. Para las asignaciones tipográficas, remitimos a la bibliografía consignada en las respectivas tablas.

${ }^{15}$ Giuseppe Di Stefano, «L'edizione dei romances viejos. Sul testo del Gaiferos libertador de Melisendra nelle stampe cinquecentesche», en «Pueden alzarse las gentiles palabras» per Emma Scoles, ed. de Ines Ravasini e Isabella Tomassetti, Roma, Bagato Libri, 2013, pp. 185-201.
} 
impresos en la Floresta de varios romances sacados de historias antiguas de los hechos famosos de los doce Pares de Francia de Damián López de Tortajada, donde estos mismos romances reiteran el recurso de la -e paragógica ${ }^{16}$. En cambio, no restituye la -e paragógica otro pliego valenciano que también se halla entre los precedentes más destacados de la mencionada Floresta. Nos referimos a RM 421, que incluso transforma forzosamente la rima grave en aguda en el siguiente verso: «a Valdouinos el Jnfan» (v. 386) ${ }^{17}$.

Como conclusión, debemos destacar que hay una serie de tendencias que marcaron el uso de la -e paragógica en el romancero carolingio impreso en el siglo XVI. Durante la segunda década de esta centuria, coincidiendo con el despegue del pliego poético como medio de difusión dirigido a un amplio público, Jacobo Cromberger comenzó a publicar varios romances carolingios en los que eliminaba sistemáticamente el incremento paragógico. En cambio, durante aquellos mismos años, otros núcleos editoriales, concretamente Burgos y Zaragoza, procedieron a publicar varios romances carolingios regularmente dispuestos en -e paragógica. El análisis métrico no deja lugar a dudas: Menéndez Pidal y otros estudiosos están en lo cierto cuando consideran que la -e paragógica no es un invento de los editores del siglo XvI, sino un fenómeno propio de los romances en los que se documenta.

No cabe duda de que los editores del siglo XvI tenían diferentes percepciones de este fenómeno. Si el taller de Jacobo Cromberger procedía a eliminar sistemáticamente la paragoge es probablemente porque era considerado como un artificio innecesario. También podemos suponer que, en estas fuentes impresas, el romancero era sobre todo un producto destinado a la lectura más que al canto, lo cual podía haber favorecido la eliminación de la -e paragógica. Pero ya desde los inicios del siglo XVI podemos encontrar testimonios impresos donde este recurso se reproduce con suma regularidad, tal como sucede con los Romances del marqués de Mantua y el Romance del conde Dirlos. En estos casos, es probable que la elevada proporción en que se halla la rima no paragógica en -á $\cdot e$ haya decantado las opciones de los impresores respectivos a evitar la rima aguda en -á. Otro aspecto destacable nos lleva a la Valencia de la segunda mitad del siglo, donde se publican diversos

${ }^{16}$ Teresa Araújo, Floresta de varios romances, sacados de las historias antiguas de los hechos famosos de los doze Pares de Francia. Agora nuevamente corregidos por Damián López de Tortajada [ed. facsímil: Valencia, Herederos de Crisóstomo Garriz por Bernardo Nogués junto al molino de la Rovella, 1642], prol. de Pere Ferré, México, Frente de Afirmación Hispanista, 2019, pp. 61 y 72; y Joan Mahiques Climent, «Romances carolingios», en Pliegos sueltos poéticos del siglo xVI en bibliotecas de Francia [ed. facsímil], ed. de Mercedes Fernández Valladares, Laura Puerto Moro y Joan Mahiques Climent, México, Frente de Afirmación Hispanista, 2 vols., en prensa.

${ }^{17}$ Teresa Araújo, ob. cit., p. 79. 
romances carolingios que más tarde serían reunidos en la Floresta de López de Tortajada. En su mayor parte, los pliegos valencianos tienden a restituir el incremento paragógico, pero hay un pliego, RM 421, que incluso fuerza la terminación de una palabra grave para mantener la rima oxítona en - $a$. Estos pliegos valencianos, con o sin -e paragógica, coinciden en la tendencia a preservar la regularidad de la rima.

\section{Tablas de romances carolingios impresos durante la etapa postincuna- ble donde se documenta el uso de la -e paragógica}

A continuación, señalamos las referencias bibliográficas incorporadas de manera abreviada en las tablas de este apartado. Utilizamos siglas o abreviaturas en los siguientes casos: FV = Mercedes Fernández Valladares, La imprenta en Burgos (1501-1600), Madrid, Arco Libros, 2 vols., 2005; Pliegos Cataluña = José Manuel Blecua, Pliegos poéticos del siglo XVI de la Biblioteca de Cataluña, Madrid, Joyas Bibliográficas, 1976; Pliegos Cracovia = María Cruz García de Enterría, Pliegos Poéticos Españoles de la Biblioteca Universitaria de Cracovia, Madrid, Joyas Bibliográficas, 1975; Pliegos Francia = Mercedes Fernández Valladares, Laura Puerto Moro y Joan Mahiques Climent, ob. cit.; Pliegos Londres = Arthur L.-F. Askins ed., Pliegos Poéticos Españoles de la British Library, Londres (impresos antes de 1601), Madrid, Joyas Bibliográficas, 3 vols., 1989-1991; Pliegos Madrid = José Antonio García Noblejas, Pliegos Poéticos Góticos de la Biblioteca Nacional, Madrid, Joyas Bibliográficas, 6 vols., 1957-1961; Pliegos Morbecq = Antonio Rodríguez-Moñino, Los Pliegos poéticos de la colección del Marqués de Morbecq (Siglo XVI), Madrid, Estudios Bibliográficos, 1962; Pliegos Praga = Ramón Menéndez Pidal, Pliegos Poéticos Españoles de la Universidad de Praga, 2 vols., Madrid, Joyas Bibliográficas, 1960; RM = Antonio Rodríguez-Moñino, ob. cit.; Supl. RM = Arthur L.-F. Askins, Víctor Infantes y Laura Puerto Moro, ob. cit. El resto de las referencias van a continuación: Vicenç Beltran, ed. cit.; Arcadio Castillejo Benavente, La imprenta en Sevilla en el siglo XVI (1521-1600), Sevilla, Universidad de Sevilla, 2019; Giuseppe Di Stefano y Mercedes Fernández Valladares, «Reaparece un pliego suelto "perdido": el Gaiferos libertador de Melisenda en la subasta Sotheby en 1936», en Rivista di Filologia e Letterature Ispaniche, 20 (2017), pp. 331-333; Mario Garvin, Scripta manent. Hacia una edición crítica del romancero impreso (siglo $X V I)$, Frankfurt am Main, Iberoamericana-Vervuert, 2007; Clive Griffin, Los Cromberger. La historia de una imprenta española en Sevilla y Méjico, Madrid, Instituto de Cooperación Iberoamericana, 1991; Víctor Infantes, «Un 
volumen viajero de impresos españoles del siglo xvi: los pliegos góticos de J.J. de Bure», en Studi Ispanici, 6 (1981), pp. 9-21; Montserrat Lamarca, La impremta a Barcelona (1501-1600), Barcelona, Biblioteca de Catalunya, 2015; Joan Mahiques Climent y Helena Rovira Cerdà, «El Romance de Guiomar y del emperador Carlos. Estudio y asentamiento de la edición de Perugia», en Hispanófila, 174 (2015), pp. 117-130; Josep Lluís Martos, art. cit.; Ramón Menéndez Pidal, ed. cit.; Frederick John Norton y Edward M. Wilson, Two spanish verse chap-books. Romançe de Amadis (c. 1515-19) Juyzio hallado y trobado (c. 1510), A facsimile edition with bibliographical and textual studies, Cambridge, Cambridge University Press, 1969; Laura Puerto Moro, «El universo del pliego poético postincunable (del despegue de la literatura popular impresa en castellano)», en eHumanista, 21 (2012), pp. 257-304; Antonio Rodríguez-Moñino, Silva de romances (Zaragoza, 15501551). Ahora por vez primera reimpresa desde el siglo XVI en presencia de todas las ediciones, Zaragoza, Publicaciones de la Cátedra Zaragoza, 1970; Id., Manual bibliográfico de cancioneros y romanceros impresos durante el siglo XVI, coord. Arthur L.-F. Askins, Madrid, Castalia, 2 vols., 1973.

Recibido: $16 / 03 / 2020$ Aceptado: 1/05/2020 
Joan Mahiques Climent

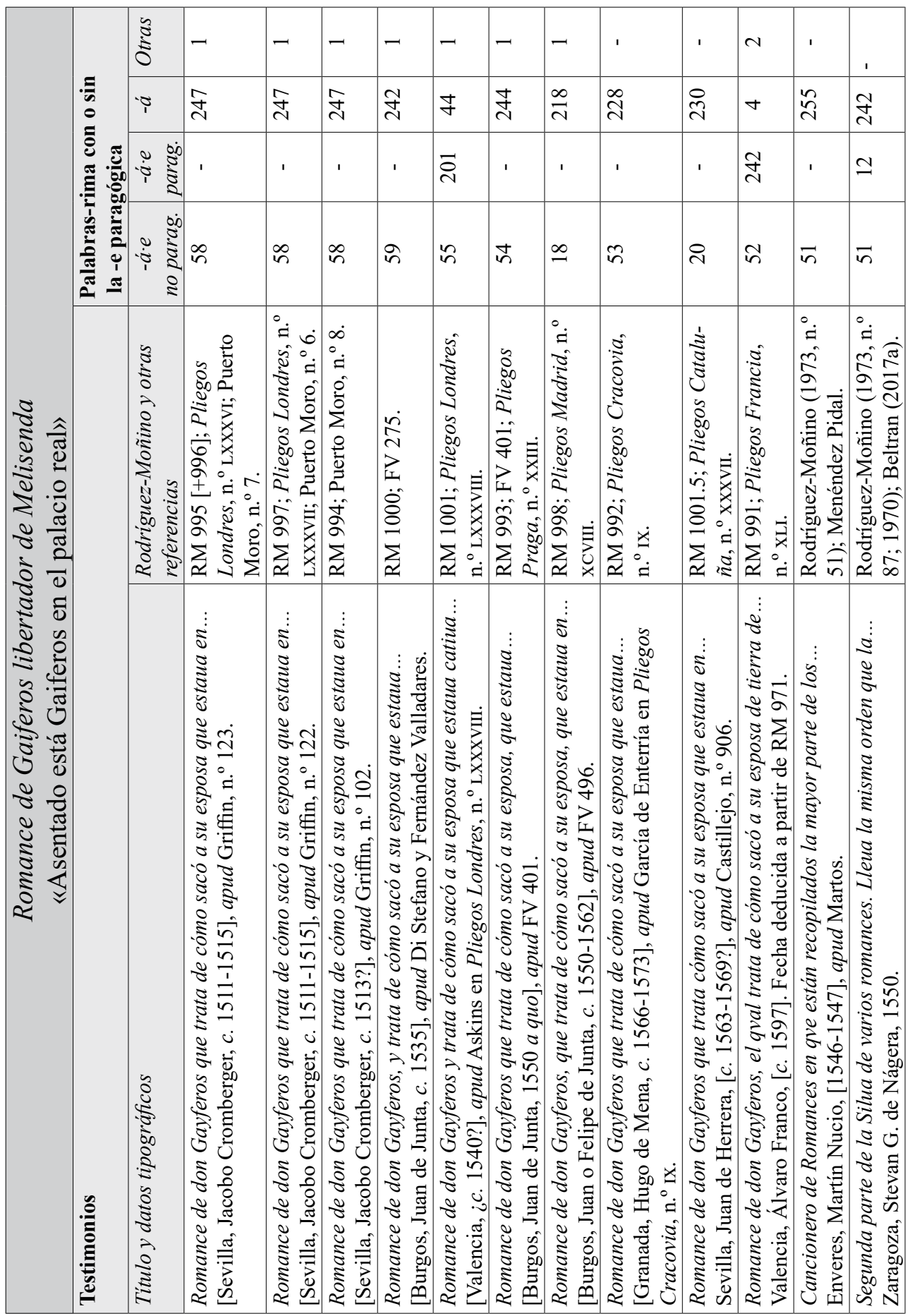


SOBRE LA PRESENCIA Y AUSENCIA DE LA -E PARAGÓGICA EN LOS ROMANCES...
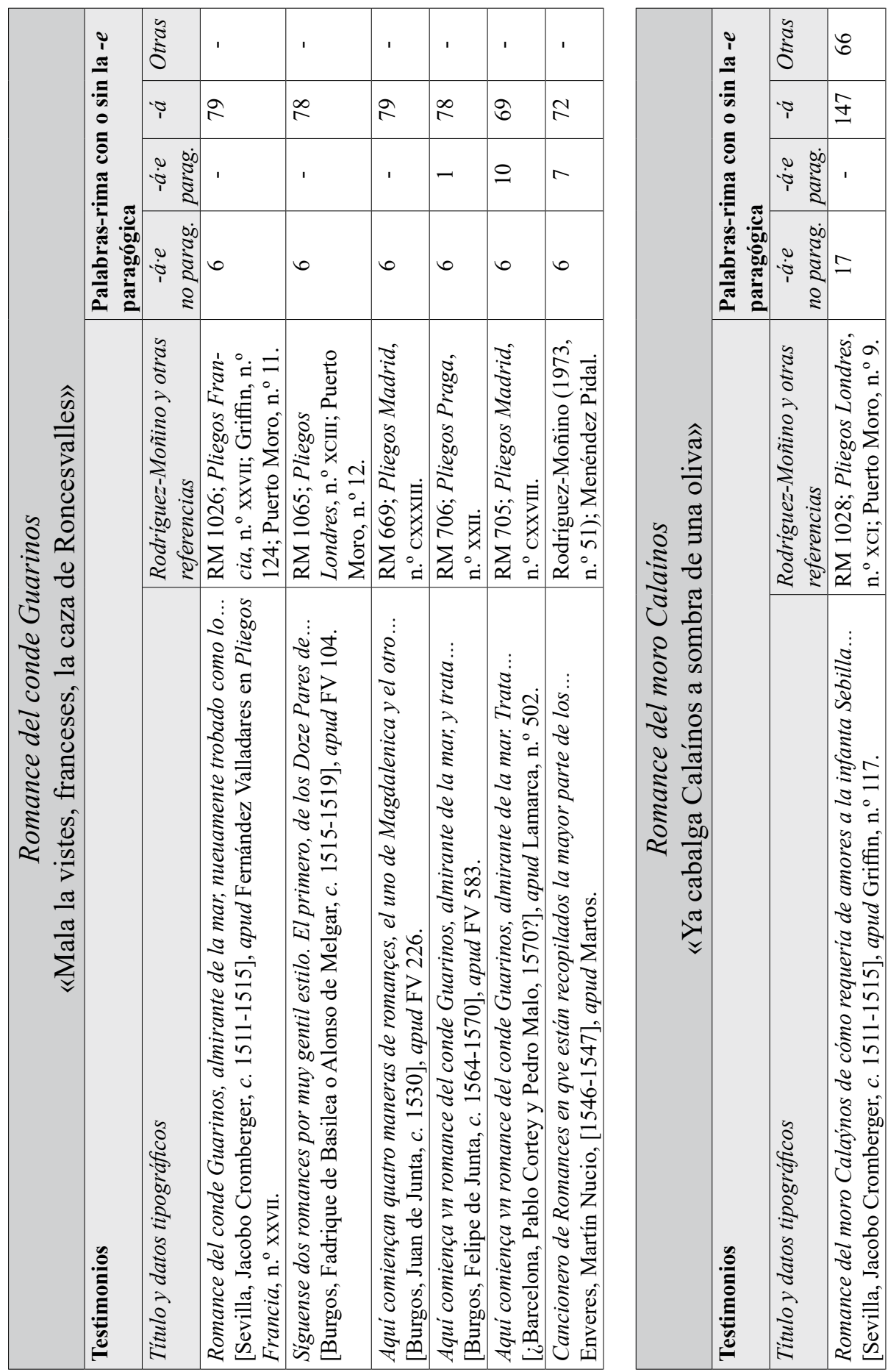

RPM, 34 (2020), pp. 159-180, ISSN: 1137-8905 


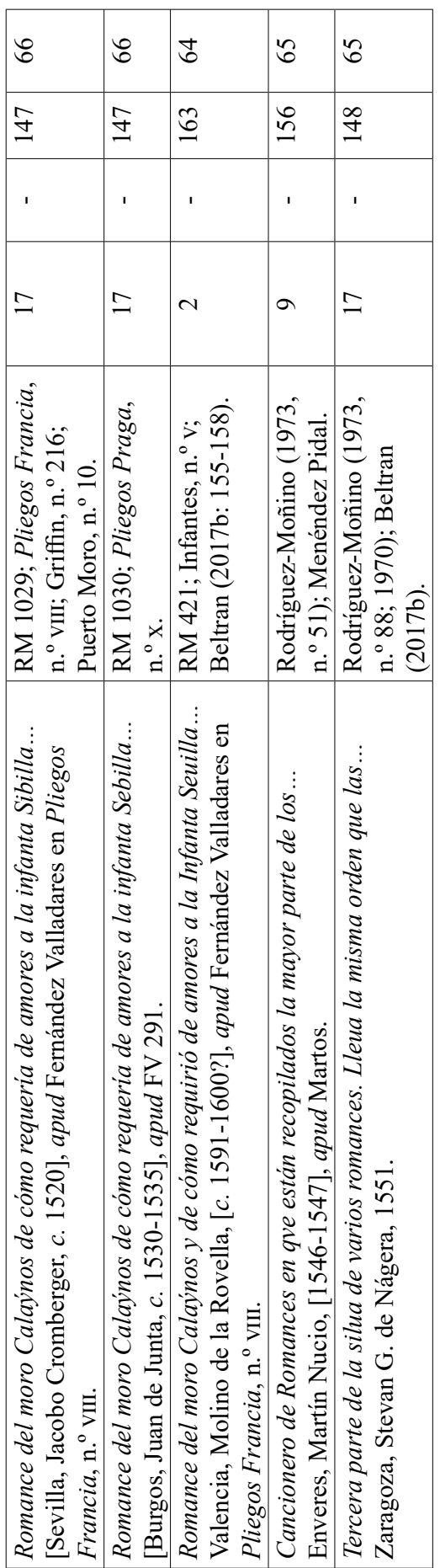

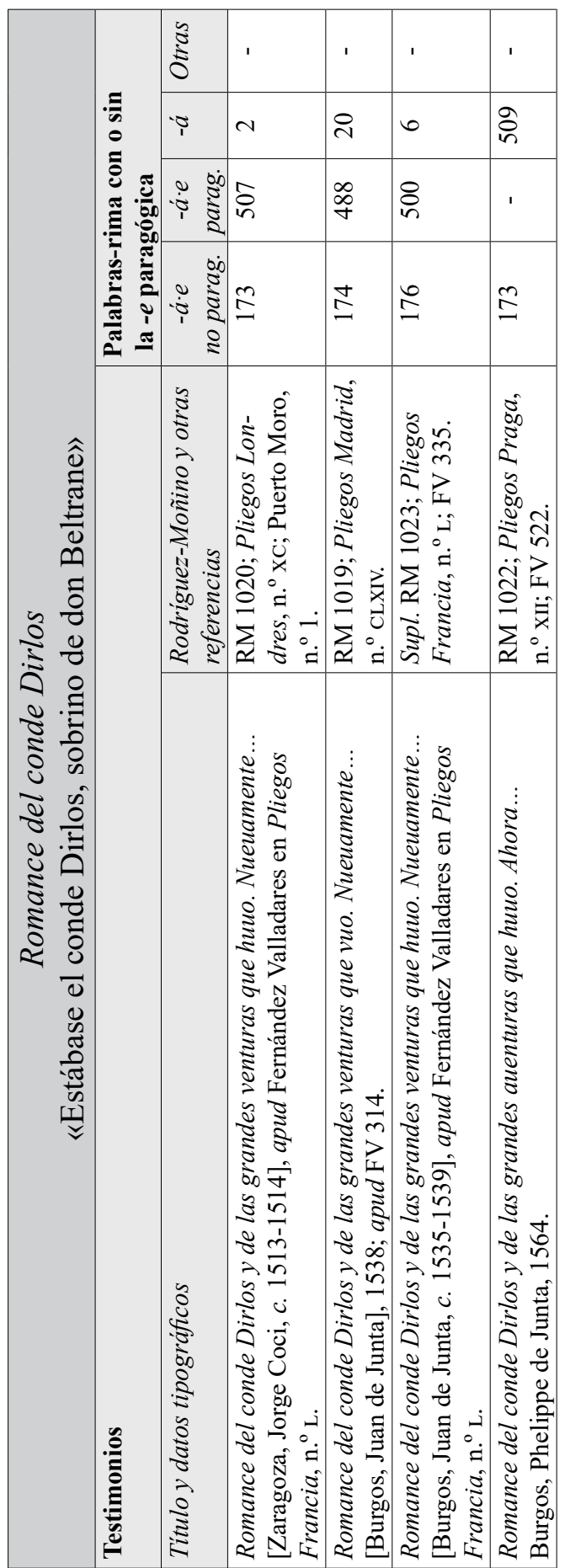

RPM, 34 (2020), pp. 159-180, ISSN: 1137-8905 
SOBRE LA PRESENCIA Y AUSENCIA DE LA -E PARAGÓGICA EN LOS ROMANCES...
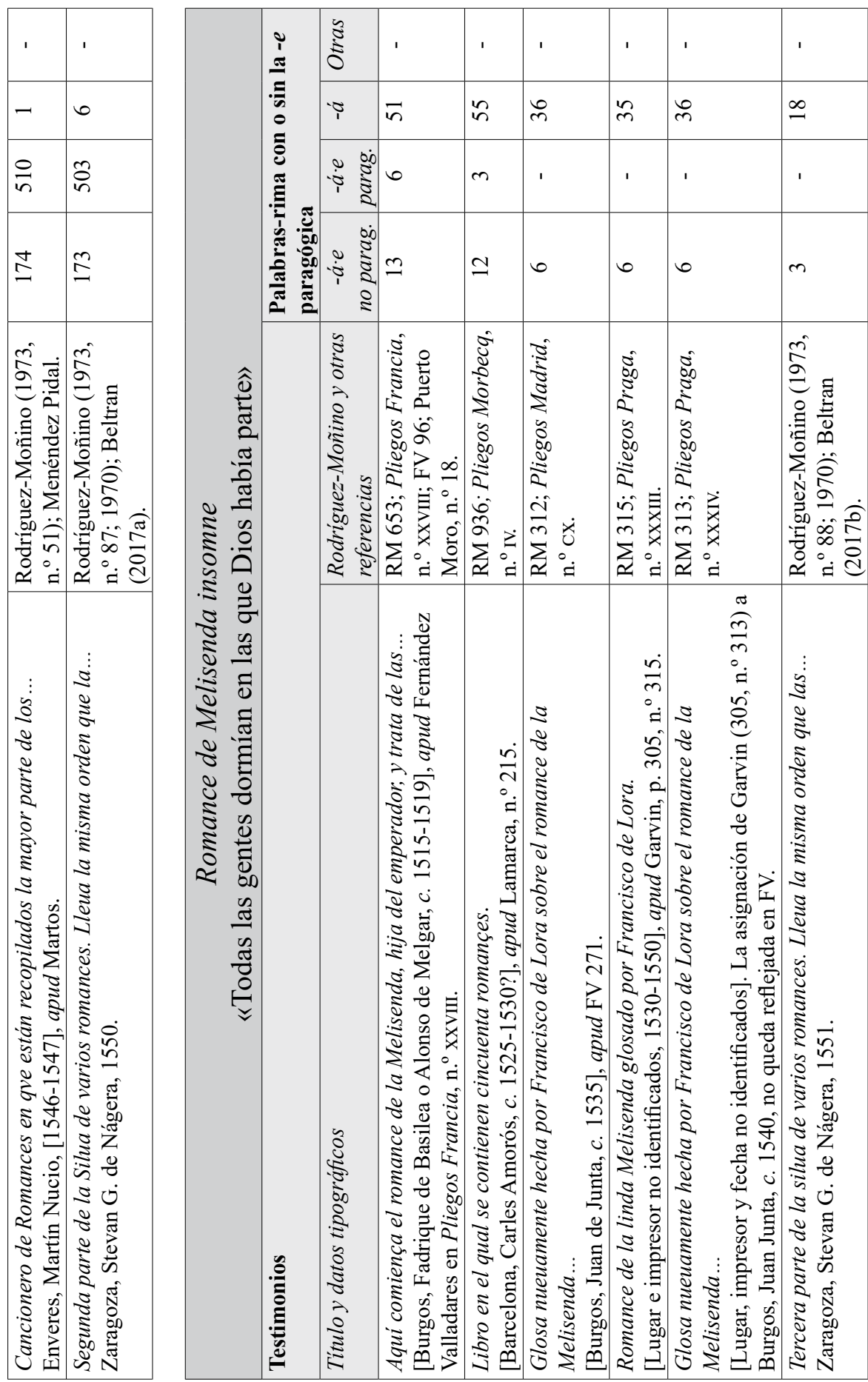

RPM, 34 (2020), pp. 159-180, ISSN: 1137-8905 
Joan Mahiques Climent

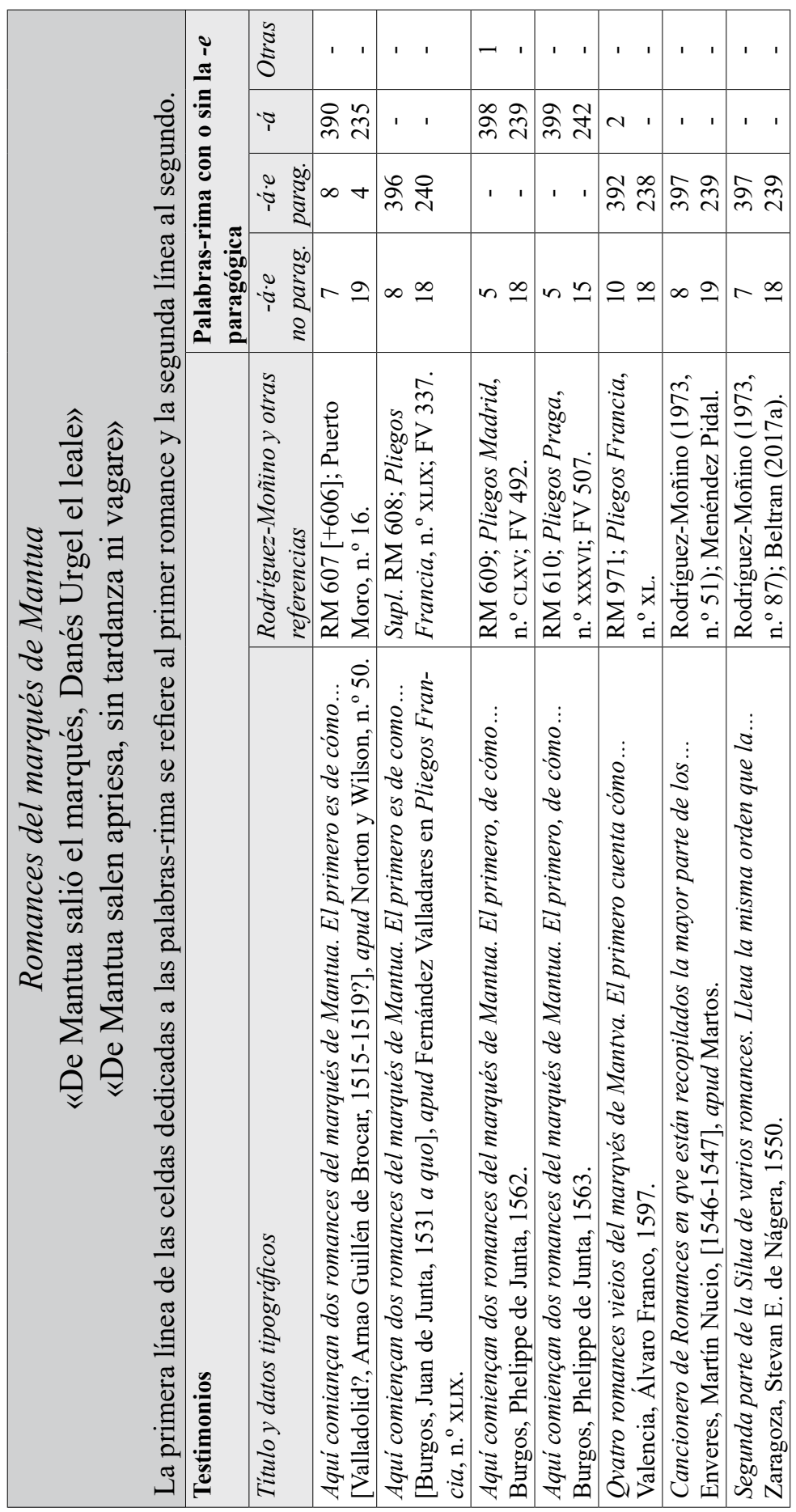


SOBRE LA PRESENCIA Y AUSENCIA DE LA -E PARAGÓGICA EN LOS ROMANCES...

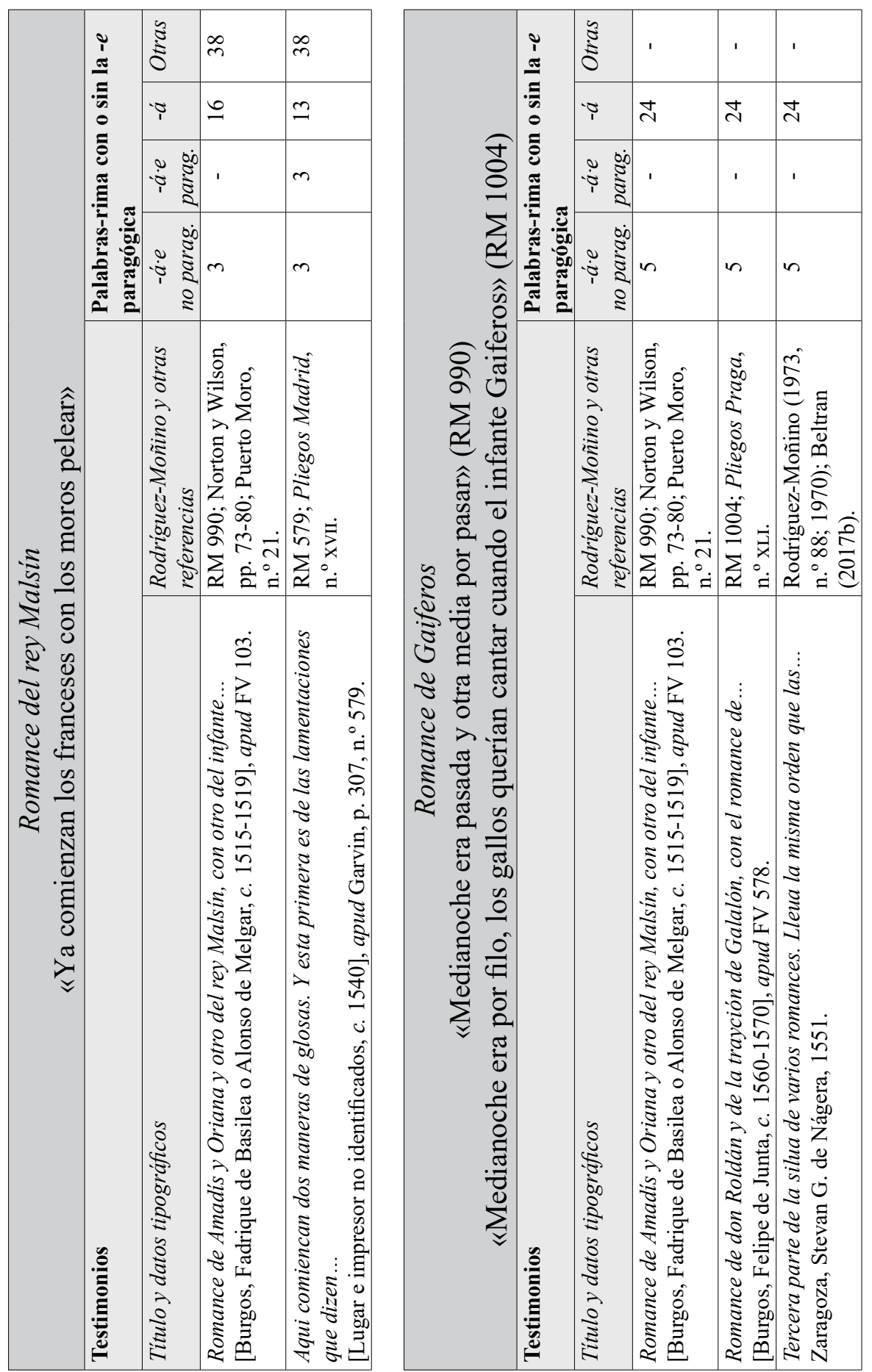

RPM, 34 (2020), pp. 159-180, ISSN: 1137-8905 
Joan Mahiques Climent

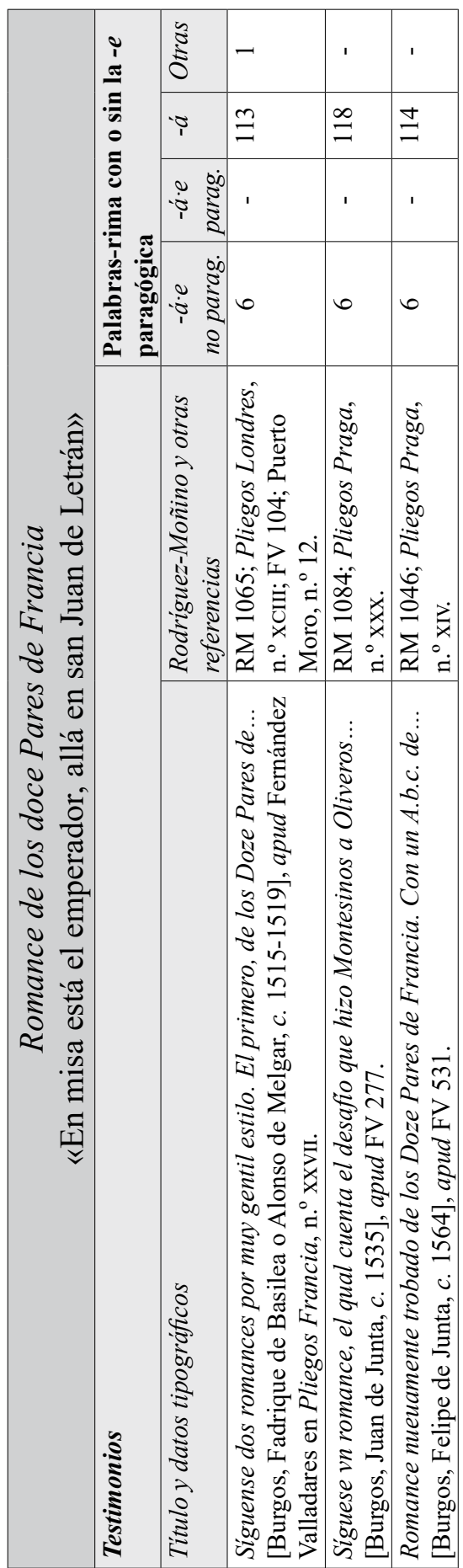

178

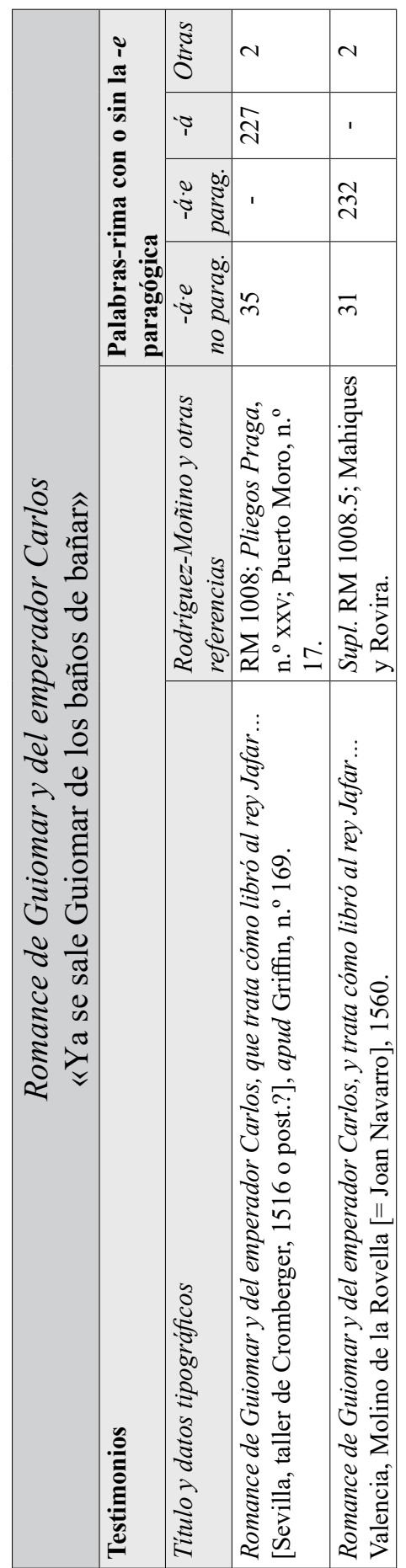

RPM, 34 (2020), pp. 159-180, ISSN: 1137-8905 


\section{$\cos$}

\section{SOBRE LA PRESENCIA Y AUSENCIA DE LA -E PARAGÓGICA EN LOS ROMANCES CAROLINGIOS IMPRESOS DURANTE EL PERÍODO POSTINCUNABLE}

RESUMEN: En este artículo se establece un corpus de once romances carolingios documentados a través de pliegos poéticos postincunables que desarrollan el recurso de la -e paragógica aplicada sobre la rima aguda en -á. Los datos más relevantes de cada uno de los once romances quedan reflejados en varias tablas ubicadas al final del artículo y referidas tanto a las rimas utilizadas como a las características de algunos de sus testimonios impresos en el siglo XVI. Concretamente, se ha procedido a registrar los pliegos sueltos poéticos conservados íntegramente en bibliotecas de acceso público más los testimonios incluidos en el Cancionero de Romances sin año, pero impreso en 1546 o 1547, o en las partes segunda y tercera de la Silva de varios romances de Esteban G. de Nájera (1550-1551). El análisis combinado de las rimas de los romances y de los datos tipográficos de sus testimonios (lugar de edición, impresor y fecha) permite establecer una serie de tendencias en el uso de la -e paragógica desde la etapa postincunable hasta el final del siglo XVI. Destaca, por ejemplo, el rechazo sistemático de la -e paragógica en los pliegos poéticos postincunables impresos en Sevilla por Jacobo Cromberger. Las ediciones burgalesas anteriores al Cancionero de romances siguen en unas ocasiones la práctica de Jacobo Cromberger, mientras que en otras incorporan la -e paragógica con suma regularidad. Durante la segunda mitad del siglo, cancioneros impresos y pliegos poéticos ejercieron una influencia mutua y en ambos sentidos.

Palabras Clave: Imprenta del siglo XVI. Postincunables. Pliegos poéticos. -E paragógica. Romances carolingios.

\section{Presence And absence of the Paragogic - $E$ in the Spanish Carolingian BALLADS PRINTED DURING THE POSTINCUNABULA PERIOD}

ABSTRACT: This paper presents a corpus of eleven Carolingian Spanish ballads («romances») documented through chapbooks printed up to 1520 in which the paragogic $-e$ is added to oxytone rhyme words ending with $-a$. Several tables put at the end of this paper refer the most relevant data regarding rhymes and 16th-century printed witnesses from each of the eleven ballads. Specifically, the tables list the presence of these eleven ballads in chapbooks held in public access libraries and in the Cancionero de romances without date, but printed in 1546 or 1547, or in the second and third parts of the Silva de varios romances printed by Esteban G. de Nájera (15501551). The whole analysis of both rhymes and typographic data (place of printing, name of publisher and date) allows us to establish several trends in the use of the paragogic $-e$ from the postincunabula period to the late 16th century. These trends take 


\section{Joan Mahiques Climent}

shape, for example, in the systematic rejection of the paragogic $-e$ in all chapbooks printed in Seville by Jacobo Cromberger. On some occasions, Burgos editions prior to the Cancionero de romances follow Jacobo Cromberger's practice, but on others they regularly put the paragogic $-e$. During the second half of the century, printed songbooks and poetic chapbooks had a mutual influence in both directions.

KeYwords: 16th-century printing. Postincunabula. Poetic chapbooks. Paragogic -e. Spanish Carolingian ballads. 